\title{
El profesional de educación física ¿quién es?
}

\section{Nelly Teresa Martínez M.}

Es costumbre separar la formación de maestros de la formación personal, así como también es frecuente plantear que la formación personal se da más en el contexto familiar, social, del grupo, de la iglesia, del trabajo, etc., que en el ambiente escolar o institución educativa, a la cual se le atribuye, preferencialmente, la formación pre-profesional o profesional y además como altamente determinante. Estas situaciones excluyentes y/o dicotómicas han llevado a pensar la realidad de la educación, desarticulada del contexto y de la experiencia de los sujetos, al extremo que los curricula para la formación de maestros. A pesar de las reflexiones hechas en este sentido, en la actualidad, siguen siendo en su mayoría yuxtaposiciones de las ciencias humanas o exactas, matizadas por la dimensión artística, técnica y tecnológica en donde la preparación anterior a la selección de una carrera se constituye en requisito académico, porque además de no ser un indicador preciso de las disposiciones del futuro estudiante, es muchas veces sólo eso, un requisito de formalidad, pues las influencias políticas y personales, suelen hacerse presentes en la selección de estudiantes universitarios cualquiera sea la universidad o modalidad profesional.

A esta situación, ya de por sí agravante, se suma el desconocimiento serio sobre los intereses, creencias, afectos y disposiciones que traen los aspirantes, el poco reconocimiento de las condiciones socioculturales en las que se ha inscrito la vida de los mismos y desde las cuales se hacen presentes experiencias y conocimientos de diversa índole.

En el caso que aquí me ocupa, la formación de maestros en Educación física, la situación, desde luego, no es diferente. Sin embargo, muchas veces se responsabiliza a las universidades y al sistema educativo escolarizado de ser los únicos orientadores de la educación del país, desconociendo así los procesos de interacción extrainstitucional en que se involucran los sujetos, y, además, asumiendo la acción educativa como unidireccional, pues no se muestra cómo los sujetos que asisten a las aulas, también orientan la formación que seda en las instituciones a pesar de lo sutil que pueda parecer. En este sentido es que entran en juego las actitudes; en la medida en que los planes de formación de maestros empiecen a respetarlas, reconocerlas y valorarlas, es decir, a hacerlas un componente vivo y significativo, los proyectos curriculares dejarán de ser el sueño de los maestros y pasaran a ser el sueño y la construcción conjunta de la siempre y eterna polaridad maestro-alumno.

Es claro que un individuo que accede a un espacio de formación trae consigo una visión del mundo, de las cosas y de las personas, pero además un cúmulo de experiencias que pueden incidir en el proceso de formación que va a emprender; es decir, que en él van a influir múltiples ámbitos y referencias. En consecuencia, los aspirantes a un programa de formación pueden traer modos de reacción, predisposiciones, valoraciones y expectativas diversas y hasta encontradas. Esto es, actitudes, no precisamente convergentes frente al objeto de estudio o programa de formación que va a cursar durante 4, 5 o 6, años que dura su carrera universitaria. Dichas actitudes, intereses y expectativas $\mathrm{y}$, en particular, aquellas referidas a la docencia serán modeladas a través del tiempo según se vaya avanzando en cosmovisiones del mundo, semestre tras semestre. Así, las universidades formadoras de maestros, quede alguna manera pretenden influir en los

\footnotetext{
* Profesora de planta, Universidad Pedagógica Nacional.
} 
estudiantes que allí se forman, entran en un conflicto entre su Proyecto Pedagógico y las expectativas de quienes a ella ingresan. Conflicto que nunca es develado y mucho menos tomado en serio. El presupuesto es: la Universidad tiene proyecto y sabe para donde debe ir el estudiante.

Reforzando lo anterior, se presenta la pedagogía en valores, hoy expresa o tácita en las áreas y campos de formación, a través de las ciencias, la tecnología, las técnicas y el arte, o formando parte de los objetivos de los planes de estudio, los cuales tratan de alcanzarse a través del desarrollo curricular, tanto desde el interior de las cátedras económicas muy interesantes, teóricamente no se como fuera de las mismas. Todo ello descontextualizado de la experiencia y formación personal que traen los sujetos, y a veces en abierta oposición a la tradición y raigambre cultural de los as pirantes a maestros, pues los diseños curriculares a pesar de presentar temáticas socio-políticas y económicas muy interesantes, teóricamente no sepiensan a la luz de seres reales de carne y hueso, es decir, desde la cultura real, no academicista. Así - las cosas, los nuevos estudiantes y en general todos los que cursan la carrera docente, se encuentran frente a un prisma en el cual visualizan una multiplicidad de fuerzas heterogéneas que no logran precisar; digamos que en ellos se hace presente el pasado como fijación y el futuro como porvenir, como modelo o aspiración por lograr, mientras que el presente lo ven como realidad inmediata; como espacio avasallador, constante, que permanece ahí como academia, pero también como vida social y familiar durante cinco o más años. El presente es como el acontecer o contexto amplio en el que se van desarrollando las demás dimensiones de la vida del sujeto: el trabajo, los amigos, el amor, el mundo de la comunicación, el devenir del país...

Pese a lo complejo de esta situación, bien valdría la pena un análisis y consideración de los tres elementos fundamentales, antes mencionados: el pasado, el futuro y el presente, ya que desde estas tres dimensiones se puede ayudar a comprender o develar el desfase que suele presentarse en la formación de maestros en Educación Física. Tal vez, estudiar estos aspectos permita encontrar los cruces entre sus conocimientos, sus necesidades e intereses, sus expectativas, valores y creencias, y las expectativas de los maestros, sí como las pensadas por los planes de estudios y las promovidas realmente en su desarrollo, porque a pesar de que la influencia multidimensional - espacio-temporal es indisociable en el ser humano, no por ello inaprensible a la reflexión; pues si es un hecho que toda sociedad para orientar sus generaciones hacia finalidades y metas ideales, que adquieren la categoría de indispensables o necesarias, instituye las formas de lograrlo, a través de roles y funciones de las instituciones formadoras de maestros que deben garantizar la preparación adecuada para un posterior desempeño como formador de nuevas generaciones, es también una responsabilidad de las mismas, reflexionar sobre los procesos que estas situaciones implican.

Sin embargo, parece que a pesar de las múltiples reformas curriculares, este proceso de formación de maestros, incluso de otros profesionales, desconoce, en cierta manera, tanto los procesos de escolarización anterior, como los marginales al sistema educativo, que es en donde se acentúa el grueso de la cultura de los individuos y en los cuales están inscritos con fuerte raigambre; creencias, valores, modos de percibir el mundo, modos de pensar, sentir y actuar, que ejercen fuerza en la constitución de la personalidad de los individuos y que, de alguna forma sutil, direccionan la formación que la Universidad ofrece, y para el particular, la Facultad de Educación física, de la Universidad Pedagógica Nacional, en la que se sigue creyendo que la formación se da en un sólo sentido: del maestro hacia el alumno. 
No puede desconocerse que es desde dichos entornos socioculturales desde donde surgen y se construyen las inquietudes, expectativas, intereses y hasta necesidades frente a la carrera, aspectos que, en cierta forma, no son tenidos en cuenta por la Facultad, en el proceso de selección ni en el de planificación y desarrollo curricular. Si en algún momento se tienen en cuenta es para desvirtuarlos, pues la tendencia que se tiene los curricula o modela, según los criterios de la entidad, del Estado o de las disciplinas académicas y pedagógicas, además de los intereses personales, científicos, filosóficos, políticos y administrativos que se conjugan desde los maestros, sin respetar el principio pedagógico fundamental de la individualidad, tan enfatizado por los pedagogos del área.

En esta situación, es necesario concebir la educación como un sinnúmero de procesos amplios de los cuales el sujeto forma parte, a través de la vida, en los múltiples espacios en los cuales le corresponda estar y en los que confluyen factores difíciles de disociar. Estos factores ejercen influencia directa o indirecta, intencionada 0 no, sobre las dimensiones del pensar, sentir y actuar de los individuos y grupos, creando condiciones que inducen a comportarse en determinadas formas; pero muchas veces más en relación con el contexto externo que con el interno del individuo, lo cual conduce a que las manifestaciones de la educación, así como las de entrevistas de ingreso, en su dimensión de exterioridad, puedan estar determinadas por muchas constantes, que en ciertos momentos, condicionan sólo cierto tipo de respuestas que llegan a ser más fuertes que los procesos o impulsos internos del individuo, impidiéndose, entonces, la manifestación de potencialidades y comportamientos consecuentes con sus predisposiciones o actitudes éticas para una selección y formación reales.

Partiendo de los enunciados anteriores y circunscribiendo dichas reflexiones al campo de la Educación física, se puede pensar que el aspirante que se inscribe para cursar dicho programa, viene de un contexto socio cultural en donde las influencias formales e informales le han llevado a construir formas de pensar, sentir y actuar particularmente sesgados, frente a la educación como proceso genérico y a la Educación física como dimensión escolar, al deporte como fenómeno social, y a la profesión como posibilidad laboral.

Evidencia de este contexto multivariado y contradictorio lo constituye la existencia de la dimensión curricular, de formación personal institucionalizada: básica primaria 0 secundaria, en la que introyecta o elabora variadas imágenes y expectativas frente a la Educación física, al profesor de la cátedra y la profesión de maestro; imágenes que pueden variar desde la dimensión interactiva y altamente pedagógica, hasta la de un tecnicismo instrumental. Completando este contexto se presenta la experiencia ajena a la institución educativa, es decir, a las prácticas consuetudinarias deportivas que le han proporcionado efectos positivos en su vida diaria en cualquier sentido y que confluyen para construir un imaginario de la profesión.

Si se confronta esta imagen vivencial escolarizada con la de sujeto social no institucionalizado, en relación a lo que le ofrecen los medios masivos de comunicación, en torno al Deporte, la Educación física y la Recreación, más el proyecto que le ofrece la Universidad, sólo es posible conformar una imagen profesional ambigua frente a la Educación física como profesión. Desde luego, esta visión no se constituye por una sumatoria simple sino como una trama de influencias en las que interactúan, además, dinámicamente los modelos de hombre y sociedad que se venden a través de todos los sistemas y medios, especialmente los masivos, en los cuales se exalta la práctica deportiva como algo digno de ser imitado por toda la sociedad, lo cual puede contribuir a una valoración inadecuada del hecho deportivo. 
Infortunadamente, esta alta valoración o exaltación del hecho deportivo y de su práctica personal o profesional no se encuentra al mismo nivel de la del ser pedagogo, maestro o educador físico. Por el contrario, el ser maestro o pedagogo no tiene el mismo reconocimiento social, se muestra conflictivo y subvalorado. Sin embargo, es posible configurar desde allí una serie de expectativas, creencias y valoraciones positivas que impulsan a los individuos a escoger e inscribirse en una universidad pedagógica para cursar el programa de Licenciatura en Educación física.

\section{La pregunta a plantear}

¿Cuáles son esas expectativas, creencias o valoraciones que tienen los aspirantes frente a la carrera? ¿Hacia qué objetos están dirigidas? ¿Hacia el ser maestro?, ¿maestro de Educación física o deportista?, o ¿hacia el tener una profesión para subsistir aunque sea como Educador Físico, ya que no se pudo ser médico? El compromiso ético de las Facultades de Educación física, sería el tomar en serio estos interrogantes y tratar de replantear, entre otros, sus procesos de admisión y de implementación curricular.

En síntesis, lo expuesto anteriormente muestra una situación en la cual se cruzan varias dimensiones, la del pasado del sujeto, su experiencia, su vivencia como deportista, el ser alumno, ver a su maestro, etc., y el futuro como modelo: configurado por una exaltación valorativa del deporte, altamente comercializado por los medios de comunicación, o el de ser maestro, que le ofrece la Universidad y la Facultad.

Ahora bien, en esta situación de discordancia, es posible que no se encuentren todos los aspirantes, habrá quienes se hallen en una sincronía total por estudiar la carrera para ser pedagogos, con lo que ello implica y lo que no implica; pero otros, tal vez, estudien pensando que es la mejor alternativa profesional para sobresalir en el campo deportivo, aunque para ello tengan que ser maestros.

Develar estas motivaciones, creencias o expectativas sería de vital importancia para el programa, no para tomarlo como criterio único de selección, sino para acogerlas como objeto de estudio y reflexión y, al reconocer su presencia, proponer lineamientos de acción curricular para orientar la formación en muchos sentidos, es decir, plantear uno o varios programas, redimensionar las prácticas pedagógicas y profesionales o construir un referente amplio para la formación que ofrece la Universidad Pedagógica, a través de la Facultad de Educación física.

Lo anterior, sin embargo, no constituye de por sí una salida, pues cabría otra interrogante: ¿Si se detectaran actitudes positivas hacia el estudio de la carrera, se podría garantizar que el desarrollo del currículo las refuerce?, o por el contrario, ¿será que las formas de interacción de los maestros de la Facultad aportan más a formar un técnico y entrenador deportivo que a un verdadero maestro y pedagogo? no se puede afirmar, por ahora, nada al respecto, y por ello es que se ve la importancia de mirar el "presente», es decir, el curso de la carrera. ¿Hacia dónde se dirige esa formación? Pienso que no es suficiente con plantear un currículo con un perfil profesional único, amplio y novedoso. Es necesario tener en cuenta, de una parte, el contexto, es decir, quiénes son, de dónde vienen, qué han vivido y qué contradicciones traen quienes se inscriben al programa de Educación física; es decir ,cuál es su pasado, su futuro y su presente. Esto estaría bien para empezar, pero siempre y en forma crítica es urgente mirar, desde ahora, el desarrollo del currículo, el entorno de las interacciones que se derivan de él, especialmente los espacios comunicativos entre maestros y estudiantes dentro y fuera de la clase, la influencia de los medios masivos y la realidad a nivel laboral y social en que se mueven 
los licenciados en este campo, si se quiere realmente dar una formación real y significativa al estudiante.

\section{Referencias}

CARRIZALES TETAMOZA, César. (1994). Consideraciones para u un teoría de la formación de docentes, en Revista Universidad Pedagógica Nacional de México.

ORSI, Alfredo. (1990). Actitudes y Conducta, en Ediciones Nueva Visión. Buenos Aires.

SABATER, Miguel. (1989). Sobre el concepto de la actitud, Revista Anales de Pedagogía, Universidad de América- España, No 7. 